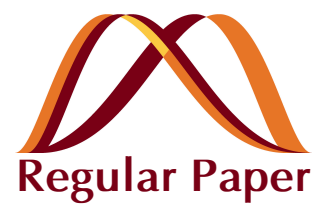

\title{
Synthesis of Carbon Nanowalls by Microwave PECVD for Battery Electrode
}

\author{
Sung Yun Kim \\ Department of Electrical Engineering, Hanbat National University, Daejeon 305-719, Korea \\ Seung Kwon Shin and Hyungchul Kim \\ Metropolitan Transportation Research Center Korea, Railroad Research Institute, Uiwang 437-757, Korea \\ Yeun-Ho Jung, Hyunil Kang, and Won Seok Choi ${ }^{\dagger}$ \\ School of Information and Communication Engineering, Hanbat National University, Daejeon 305-719, Korea \\ Gi Back Kweon \\ Department of Electric Automation, Daeduk University, Daejeon 305-715, Korea
}

Received June 29, 2015; Revised July 20, 2015; Accepted July 31, 2015

\begin{abstract}
The microwave plasma enhanced chemical vapor deposition (PECVD) system was used to grow a carbon nanowall (CNW) on a silicon (Si) substrate with hydrogen $\left(\mathrm{H}_{2}\right)$ and methane $\left(\mathrm{CH}_{4}\right)$ gases. To find the growth mechanism of $\mathrm{CNW}$, we increased the growth time of CNW from 5 to $30 \mathrm{~min}$. The vertical and surficial conditions of the grown CNWs according to growth time were characterized by field emission scanning electron microscopy (FE-SEM). Energy dispersive spectroscopy (EDS) measurements showed that the CNWs consisted solely of carbon.
\end{abstract}

Keywords: Carbon based nanomaterial, Carbon nanowall, Microwave plasma enhanced vapor deposition, Carbon electrode, Growth time

\section{INTRODUCTION}

Carbon-based nano materials such as fullerene (found in 1985) [1] and carbon nanotube (CNT, found in 1991) [2] have been studied by many researchers. In particular, graphene, which was separated from a layer of graphite, has become the focus of attention due to its numerous special characteristics [3]. The two-dimensional nanostructure with vertically grown graphene is called a carbon nanowall (CNW), which is chemically stable and has excellent mechanical strength with large surface area

${ }^{\dagger}$ Author to whom all correspondence should be addressed:

E-mail:wschoi@hanbat.ac.kr

Copyright $(2015$ KIEEME. All rights reserved.

This is an open-access article distributed under the terms of the Creative Commons Atribution Non-Commercial
License (httr:///lreativecommons org License (http://creativecommons.org/licenses by-nc/3.0) which permits unrestricted
distribution, and reproduction in any medium, provided the orignal work is properly cited.
Furthermore, due to its shape as a vertically grown graphene, CNW has the advantages of high electrical conductivity and electron affinity, and has the highest surface density among carbonbased nanostructures [4-7]. Using CNW electrodes instead of porous carbon electrodes to increase the reaction area of existing graphite electrodes can dramatically improve the performance of devices due to the high reaction area and stable properties of CNW. In this study, CNW was synthesized through microwave plasma enhanced chemical vapor deposition (PECVD) by using methane $\left(\mathrm{CH}_{4}\right)$ and hydrogen $\left(\mathrm{H}_{2}\right)$ as reaction gases. The physical characteristics of the grown CNW were observed in accordance with the growth time to identify the growth mechanism of CNW.

\section{EXPERIMENTS}

CNW was synthesized using a microwave PECVD (Woosin 
CryoVac, CVD-R2) on a p-type $\mathrm{Si}(100)$ substrate with $\mathrm{CH}_{4}$ and $\mathrm{H}_{2}$ as reaction gases. The substrate was ultrasonically cleaned in trichloroethylene (TCE), acetone, methanol, and deionized (DI) water consecutively for $10 \mathrm{~min}$, followed by treatment for $45 \mathrm{sec}$ onds in HF solution diluted with DI water at the mixture ratio of 10:1 to remove native oxide on the Si substrate. A chamber was vacuumed to $10^{-5}$ Torr. Then, $30 \mathrm{sccm}$ and $15 \mathrm{sccm}$ of $\mathrm{CH}_{4}$ and $\mathrm{H}_{2}$, respectively, were inserted into the chamber. In this step, CNW was synthesized with a microwave power of $1 \mathrm{~kW}$ at the temperature of $800^{\circ} \mathrm{C}$ while the vacuum in the chamber was maintained at 1 mTorr. After the synthesis, the chamber was cooled down to below $100^{\circ} \mathrm{C}$ while the vacuum inside the chamber was maintained at $10^{-5}$ Torr. In this study, the CNW growth time varied from 5 to $30 \mathrm{~min}$ with intervals of $5 \mathrm{~min}$. The thickness and surface condition of the CNW were examined to analyze the characteristics of the synthesized CNW. A field emission scanning electron microscope (FE-SEM, Hitachi, S-4800) was used for the analysis, while the composition was analyzed using energy dispersive spectroscopy (EDS).

\section{RESULTS AND DISCUSSION}

Figure 1 shows the FE-SEM surface analysis of CNWs according to growth time. No CNW growth was observed for a synthesis of less than 10 min. In Fig. 1(a), the CNW growth was observed in the SEM photograph of the specimen synthesized for $10 \mathrm{~min}$.

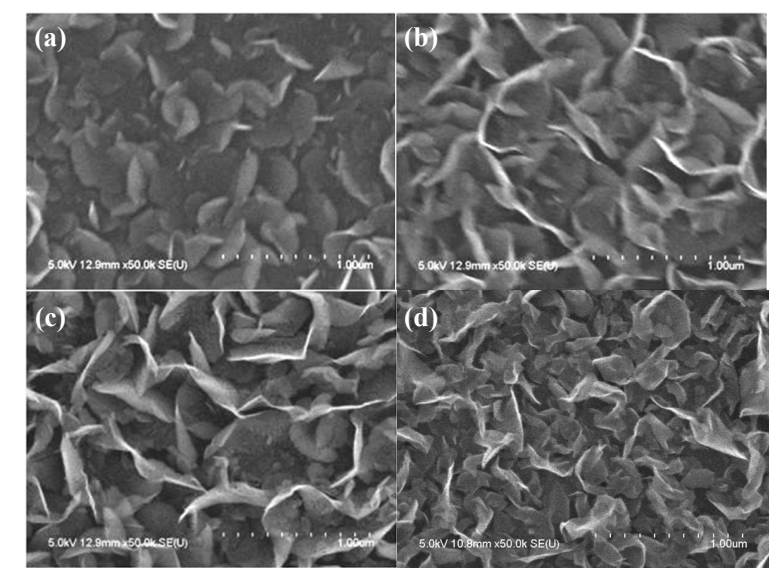

Fig. 1. Surficial SEM images of CNWs according to growth time: (a) 10 min, (b) $15 \mathrm{~min}$, (c) $20 \mathrm{~min}$, and (d) $30 \mathrm{~min}$.

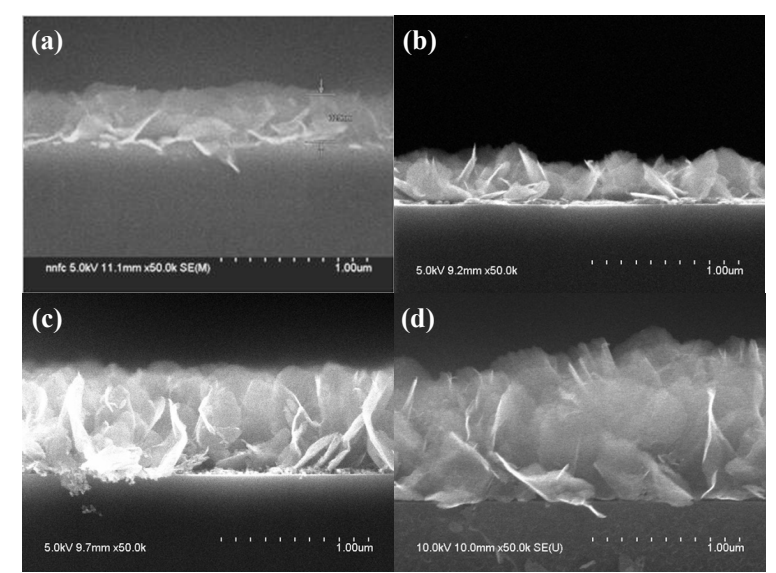

Fig. 2. Cross-sectional SEM images of CNWs according to growth time: (a) $10 \mathrm{~min}$, (b) $15 \mathrm{~min}$, (c) $20 \mathrm{~min}$, and (d) $30 \mathrm{~min}$.

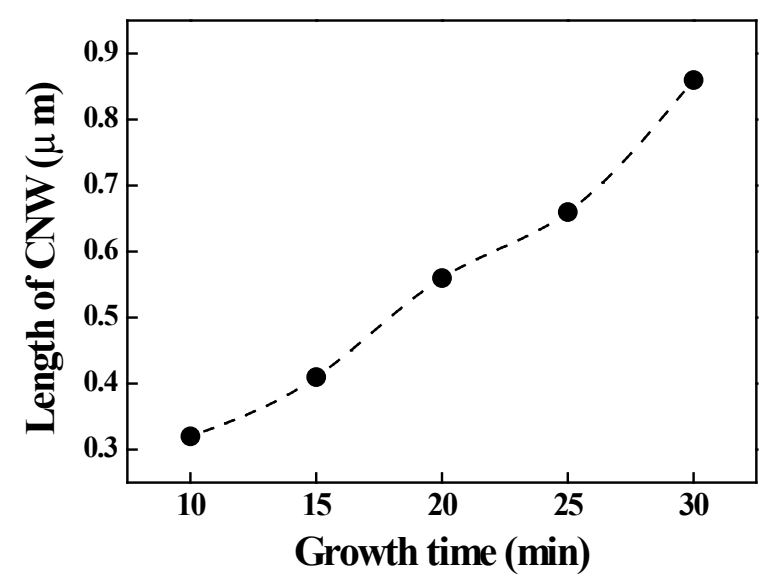

Fig. 3. Average length of CNW according to growth time.
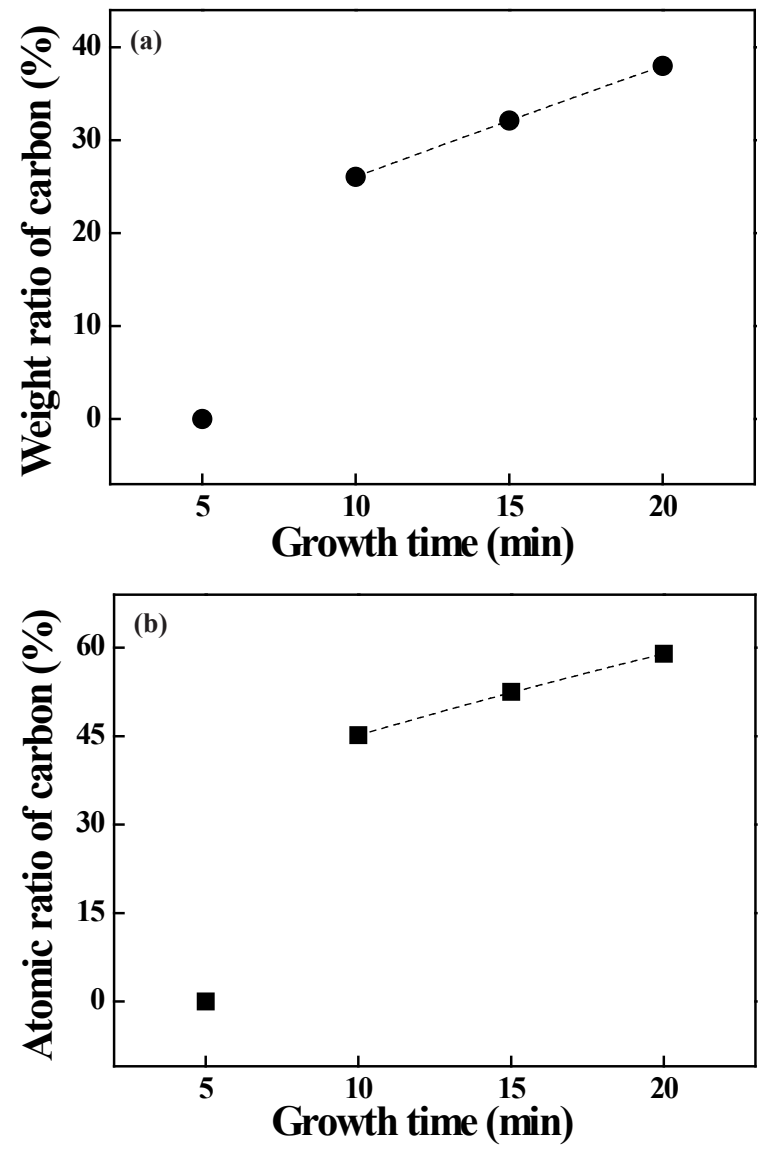

Fig. 4. EDS analysis of CNWs according to growth time: (a) weight \% of carbon, (b) atomic \% of carbon.

The SEM photograph of the specimen synthesized for $15 \mathrm{~min}$ (Fig. 1(b)) captured the nano structure of CNW which grew more vertically than that shown in the SEM image of the specimen synthesized for $10 \mathrm{~min}$. For the specimen synthesized for $20 \mathrm{~min}$, the synthesized CNW formed a general shape. In the case of 30 min synthesis, the CNW grew more densely.

Figure 2 presents the FE-SEM cross-sectional image of CNW according to growth time. We checked the height of CNWs from these cross-sectional SEM images and the average height of CNW is summarized in Fig. 3. The CNW thickness increased almost linearly as the growth time increased. The average length 
Table 1. EDS analysis of CNWs.

\begin{tabular}{ccccc}
\hline \multirow{2}{*}{$\begin{array}{c}\text { Growth Time } \\
(\mathrm{min})\end{array}$} & $\mathrm{Si}$ & $\mathrm{C}$ & $\mathrm{Si}$ & $\mathrm{C}$ \\
\cline { 2 - 5 } Weight\% & \multicolumn{3}{c}{ Atomic\% } \\
\hline \hline 5 & 100 & 0 & 100 & 0 \\
\hline 10 & 73.93 & 26.07 & 54.81 & 45.19 \\
\hline 15 & 67.88 & 32.12 & 47.47 & 52.53 \\
\hline 20 & 64.74 & 35.26 & 43.99 & 56.01 \\
\hline 30 & 61.91 & 38.00 & 41.01 & 58.99 \\
\hline
\end{tabular}

of the CNW synthesized for 10 min was $0.32 \mu \mathrm{m}$, whereas that of the CNW synthesized for $20 \mathrm{~min}$ was $0.56 \mu \mathrm{m}$, and increased to $0.86 \mu \mathrm{m}$ for the CNW synthesized for $30 \mathrm{~min}$.

Table 1 summarizes the results of the EDS composition analysis of the CNWs synthesized on the Si substrate according to growth time. When the CNW was synthesized on the Si substrate for $5 \mathrm{~min}$, no carbon composition was observed. This result is summarized in Fig. 4. A carbon composition was found after 10 min and linearly increased according to growth time. This analysis showed that CNW was composed of pure carbon, as no other elements were found except for $\mathrm{Si}$, which comprises the substrate.

\section{CONCLUSIONS}

In this study, we synthesized CNWs on Si substrate using microwave PECVD with $\mathrm{CH}_{4}$ and $\mathrm{H}_{2}$ gases as reaction gases. The characteristics of the synthesized CNWs were analyzed according to varying growth time. The SEM analysis confirmed the synthesis of CNWs at the growth time of $10 \mathrm{~min}$ or longer, and the CNWs grew to a general shape after $20 \mathrm{~min}$. The growth of CNWs was proportionate to the growth time and the growth rate increased after $20 \mathrm{~min}$. The EDS analysis showed that CNW was mainly composed of pure carbon, as no other elements other than Si comprising the substrate were measured. This study experimentally demonstrated that growth time is important as it influences the CNW growth and growing period.

\section{ACKNOWLEDGMENT}

This research was supported by a grant from the R\&D program of the Korea Railroad Research Institute (PK1503B), Republic of Korea.

\section{REFERENCES}

[1] H. W. Kroto, J. R. Heath, S. C. O'Brien, R. F. Curl, and R. E. Smalley, Nature, 318, 14 (1985). [DOI: http://dx.doi. org/10.1038/318162a0]

[2] S. Iijima, Nature, 354, 56 (1991). http://dx.doi. org/10.1038/354056a0]

[3] K. S. Novoselov, A. K. Geim, S. V. Morozov, D. Jiang, Y. Zhang, S. V. Dubonos, I. V. Grigorieva, and A. A. Firsov, Science, 306, 666 (2004). [DOI: http://dx.doi.org/10.1126/science.1102896]

[4] S. Stankovich, D. A. Dikin, G.H.B. Dommett, K. M. Kohlhaas, E. J. Zimney, E. A. Stach, R. D. Piner, S. T. Nguyen, and R. S. Ruoff, Nature, 286, 282 (2006). [DOI: http://dx.doi.org/10.1038/nature04969]

[5] M. Hiramatsu and M. Hori, Carbon Nanowalls (Springer, New York, 2010). [DOI: http://dx.doi.org/10.1007/978-3-211-997185]

[6] D. Yoon, H. Moon, H. Cheong, J. Choi, J. Choi, and B. Park, J. Korean Phys. Soc., 55, 1299 (2009). [DOI: http://dx.doi. org/10.3938/jkps.55.1299]

[7] Z. Hu, K. Park, and K. Yi, J. Korean Phys. Soc., 54, 921 (2009). [DOI: http://dx.doi.org/10.3938/jkps.54.586] 